\title{
Non-Haemolytic Childhood Cholelithiasis Managed Laparoscopically: A Report Of 15 Cases.
}

\author{
${ }^{1}$ Ranendra Hajong, ${ }^{1}$ Dathiadam Tongper, ${ }^{1}$ Peter Daniel S Khariong, \\ ${ }^{1}$ Naloh Mibang \\ ${ }^{I}$ Department of General, NEIGRIHMS, Shillong, Meghalaya, India
}

\begin{abstract}
A retrospective review of the patients with childhood cholelithiasis managed by laparoscopic cholecystectomy at NEIGRIHMS Hospital in North East India between January 2009 and December 2012 was done. Data reviewed were the following - patient demographics, clinical history, hematological studies, imaging studies, operative techniques, postoperative complications and recovery and also the final histopathological diagnosis from the gallbladder specimen.

During the study period of 3 years, 15 children (all females) were managed in the department of surgery of this hospital by laparoscopic cholecystectomy and none of the patients had any history suggestive of any hemolytic disorders. The mean age was 7.6 years (range 3 to 14 years). Pigment stones were found in eight of the patients and the remaining seven patients had mixed stones. The mean duration of operation was 45 mins (range 30- 60 mins). No significant postoperative complications occurred in any of the patients. The average duration of hospital stay was 2 days (range $2-4$ days).

The incidence of cholelithiasis in children is not very common, but non-hemolytic causes may also lead to gallstone formation as in adult population. Laparoscopic cholecystectomy is a very safe and efficacious management option for cholelithiasis in children.
\end{abstract}

Key Words: Cholelithiasis, childhood, non haemolytic causes, laparoscopic cholecystectomy, indigenous retrieval bag.

\section{Introduction:}

Diseases of the gallbladder such as cholecystitis or cholelithiasis are considered to be rare in children. But due to the extensive use of ultrasound scanning an increasing number of children have been identified to have cholelithiasis and its various manifestations. In a population based study, prevalence of gallstones and biliary sludge in children was of $1.9 \%$ and $1.46 \%$ respectively (1). Cholelithiasis, although increasing in frequency in children, is still far less common than in the adult population (2). The nature of the disease process is different in children as compared to adults, with a higher proportion of pigment stones and less cholesterolbased stone disease in the paediatric population, especially those younger than 10 years of age (3). Guidelines for management of cholelithiasis are available for adults. Cholecystectomy is recommended for symptomatic patients and for those asymptomatic with a predisposition for malignancy (calcified gallbladder wall or family history of gallbladder cancer). For asymptomatic patients an expectant management with periodical clinical and echo graphic controls is recommended $(4,5)$. On the contrary, little is known about natural history and management of cholelithiasis in childhood. So far, guidelines for management of children with gallstones are lacking. Surgical options for paediatric cholelithiasis include open or laparoscopic cholecystectomy (6). At the present, laparoscopic technique is considered the gold standard for cholecystectomy in children for reduced pain, absence of an upper abdominal incision and scar formation and a shorter period of hospitalization (7- 10). The present study was conducted to study the incidence of non- hemolytic cholelithiasis in children and the role of laparoscopic cholecystectomy in the management of childhood cholelithiasis.

\section{Materials and methods:}

A retrospective review of all the children who underwent LC for cholelithiasis at NEIGRIHMS Hospital in North East India between January 2009 and December 2012 was done. The patient medical records were examined and the data pertaining to demographic information, clinical history, diagnosis, operative findings and operative technique, postoperative complications and recovery and the final histopathological diagnosis were obtained. LC was performed by the same surgeon using the standard four ports technique. A 10 $\mathrm{mm}$ umbilical camera port was inserted using the open technique in all the cases. One more $10 \mathrm{~mm}$ port was inserted in the epigastrium, which was also used for retrieval of the gall bladder specimen. One $5 \mathrm{~mm}$ ports were placed in the right mid-clavicular line in the hypochondrium or the lumbar region, and another $5 \mathrm{~mm}$ port was inserted in the right anterior axillary line, to help the assistant surgeon grasp the fundus of the gall bladder for retraction. The pneumoperitoneum was adjusted according to the size of the child, maintaining a mean pressure 
of $4.5 \mathrm{mmHg}$ (range 3- $7 \mathrm{mmHg}$ ). Commercially available small plastic bags used for packing betel nuts were used as a retrieval bag after plasma sterilisation (Figures 1,2,3 and 4).

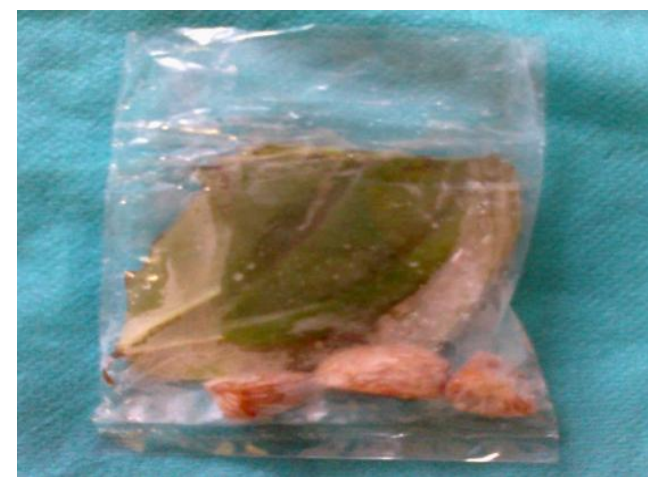

Figure 1 showing plastic bag being used for packing betel nut and leaves

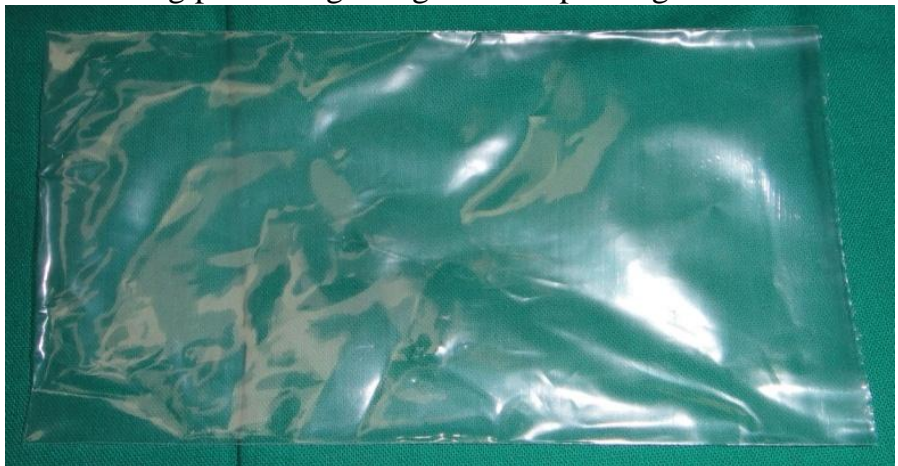

Figure 2 showing same plastic bag after plasma sterilisation.

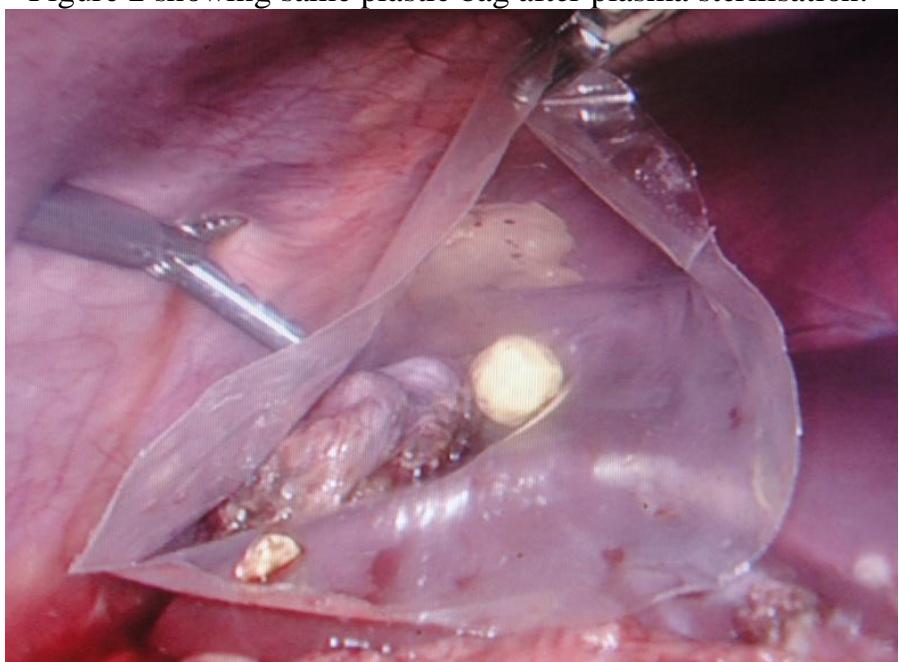

Figure 3 showing plastic bag inside abdomen with gall bladder and stone inside.

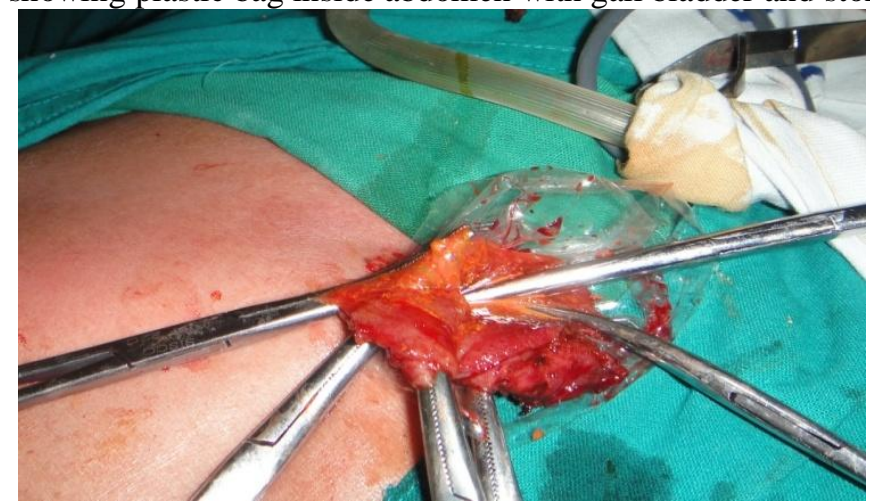

Figure 4 showing plastic bag and gall bladder being extracted through epigastric port. 
These bags are easily available and very cheap and also strong enough to be used as a retrieval bag. Intraoperative cholangiography was not deemed to be necessary in any of the patients. The patients were discharged when they were able to tolerate a regular diet and were ambulatory. They were followed up in the outpatient clinic at least once after the discharge.

During the study period, 15 patients underwent LC for cholelithiasis. The mean age was 7.6 years (range 3 to 14 years). Twelve patients $(80 \%)$ presented with symptoms related to biliary tract disease (right upper quadrant or epigastric pain, nausea, vomiting and food intolerance) one patient presented with acute pancreatitis who was managed conservatively at first and the laparoscopic cholecystectomy was done after 4 weeks, two patients were discovered to have cholelithiasis while performing ultrasonography of the abdomen for other symptomatology Duration of symptoms at diagnosis varied from 15 days to 3 months (mean -1.8 months). Risk factors for development of gallstones were not found in any of the patients. After a complete workup, it was found that none of the patients were detected with having haemolytic disorders such as sickle cell disease, thalassemia or hereditary spherocytosis. Complete haemogram, peripheral blood smear and liver function tests were found within normal limits in all the patients. All the children underwent an abdominal ultrasound and were detected to have single or multiple gallstones. One child was found to have acute pancreatitis. All children underwent elective laparoscopic cholecystectomy with single dose of intravenous antibiotic during operation. The mean duration of operation was 45 mins (range 30- 60 mins). No significant postoperative complications occurred in any of the patients. The average duration of hospital stay was 2 days (range $2-4$ days). No abdominal drains were used in any of the patients.

\section{Discussion:}

Although cholelithiasis is considered as an uncommon condition in children, recent series document an increasing detection of this disorder (1). This may be explained by the increased availability and use of the abdominal ultrasonogram in children. Pediatric cholelithiasis was viewed as a disease of prematurity, usually related to total parenteral nutrition. Various risk factors for cholelithiasis in children include haemolytic disorders, obesity, family history of gallstones, abdominal surgery, IgA deficiency, cystic fibrosis, therapy with ceftriaxone and Gilbert's disease. None of the patients in this series had any of the above mentioned risk factors. The incidence of idiopathic cholelithiasis in other reported series varies from 23 to $52.5 \%(11,12)$. The mechanism of gallstone formation in these children is probably due to a combination of interacting processes, including, dehydration, and transient hepatic dysfunction, dietary, inflammatory, hereditary and endocrine influences, which affect the composition of bile (13).

Approximately $80 \%$ of the adults with gallstone are asymptomatic $(14,15)$. However, in children, asymptomatic gallstones are less frequent, with a reported incidence of 10 and $33 \%$ in two different studies (12, 13). In the present series, the incidence of asymptomatic gallstone was $10 \%$. Routine intraoperative assessment for common duct stones was not done in the present series. Shawn et al., have reported that the incidence of subclinical common bile duct stones is low in children (2). This finding has also been described in a small prospective paediatric study (16). In the present series, as there was no evidence of common bile duct stones or altered liver function tests preoperatively in any of the patients, an intraoperative cholangiogram was not done. None of the patients had any evidence of residual ductal stones during the follow up period.

Although the prevalence of cholelithiasis in children is increasing, little information is available about the management of this disorder in childhood. There are only few data on paediatric cholelithiasis and in the majority of cases the studies were performed on a limited number of patients. Claudia Della Corte et al (11) in their National multicenter study about the management of cholelithiasis in Italy evaluating a large cohort of children observed at Medical and Surgical Department linked to SIGENP, have opined that both diagnostic approach and therapeutic strategies were extremely heterogeneous. They have also concluded that laparoscopic cholecystectomy was an efficacious and safe procedure in the treatment of paediatric gallstones for the low rate of post-operative complications (3\%) and post-cholecystectomy syndrome (4.7\%). The histological analysis of the removed gallbladders showed structural alterations such as chronic cholecystitis, papillomatosis and adenoma in the majority of cases; in only few cases the gallbladder wall was normal. Therefore, for long life expectancy of children, expectant management may not be safe in paediatric patients (11). In fact, in contrast to adults in whom the natural history of gallstones is well documented, in children it is not known. In adults only $1 \%-4 \%$ per year will develop symptoms or complications of gallstones disease; only $10 \%$ will develop symptoms in the first five years after diagnosis and approximately $20 \%$ by 20 years (17-19).

The mean duration of operation in this series was 25.5 mins (range 20- 45 mins).. This duration was between 70 and 80 minutes in other reported series $(2,20)$. The comparison of various parameters between LC and open cholecystectomy in one study reported significantly less duration of hospital stay and decreased overall cost in patients undergoing LC (20). The other advantages of LC, such as, decreased pain, avoidance of upper abdominal muscle cutting incision, faster return to activity and cosmetically better scar, are welldocumented (21-23). 


\section{Conclusion:}

Laparoscopic cholecystectomy (LC) is confirmed to be a safe and efficacious treatment modality for paediatric cholelithiasis. The cause for increased incidence of paediatric cholelithiasis and their natural history needs to be further evaluated.

Conflict of interest statement: None.

\section{References:}

[1]. Wesdorp I, Bosman D, de Graaff A, Aronson D, van der Blij F, Taminiau J. Clinical presentations and predisposing factors of cholelithiasis and sludge i children. J Pediatr Gastroenterol Nutr 2000;31:411-417.

[2]. Kaechele V, Wabitsch M, Thiere D, Kessler AL, Haenle MM, Mayer H, et al. Prevelance of gallbladder stone disease in obese children and adolescents: Influence of the degree of obesity, sex and pubertal development. J Pediatr Gastroenterol Nutr 2006;42:66-77.

[3]. Bailey PV, Connors RH, Tracy TF Jr, Sotelo- Avila C, Lewis JE, Weber TR. Changing spectrum of cholelithiasis and cholecystitis in infants and children. Am J Surg 1989;158: 585-588.

[4]. Treatment of gallstone and gallbladder disease. SSAT patient care guidelines. J Gastrointest Surg. 2004; 8: 363-364.

[5]. Ransohoff DF, Gracie WA. Treatment of gallstones. Ann Intern Med. 1993;119:606-619

[6]. Kim PC, Wesson D, Superina R, Filler R. Laparoscopic cholecystectomy versus open cholecystectomy in children: which is better? J Pediatr Surg. 1995;30:971-973

[7]. Esposito C, Gonzalez Sabin MA, Corcione F, Sacco R, Esposito G, Settimi A. Results and complications of laparoscopic cholecystectomy in childhood. Surg Endosc. 2001;15:890-892.

[8]. Mattioli G, Repetto P, Carlini C, Granata C, Montobbio G, Cagnazzo A, Barabino A, Gandullia P, Jasonni V. Medium-term results after cholecystectomy in patients younger than 10 years. Surg Endosc. 2001;15:1423-1426.

[9]. Holcomb GW 3rd, Morgan WM 3rd, Neblett WW 3rd, Pietsch JB, O'Neill JA Jr, Shyr Y. Laparoscopic cholecystectomy in children: lessons learned from the first 100 patients. J Pediatr Surg. 1999;34:1236-1240.

[10]. Clements RH, Holcomb GW 3rd. Laparoscopic cholecystectomy. Curr Opin Pediatr. 1998;10:310-314

[11]. Claudia Della Corte, Diego Falchetti, Gabriella Nebbia, Marisa Calacoci, Maria Pastore, Ruggiero Francavilla, Matilde Marcellini, Pietro Vajro, and Raffaele Iorio. Management of cholelithiasis in Italian children: A national multicenter study. World J Gastroenterol 2008; 14(9): 1383-1388.

[12]. Holcomb GW, Jr, O'Neill JA, Jr, Holcomb GW., 3rd Cholecystitis, cholelithiasis and common duct stenosis in children and adolescents. Ann Surg. 1980;191:626-44

[13]. Babbitt DP. Gallstones in children. Am J Dis Child. 1956;92:5-8.

[14]. Pieretti R, Audldist AW, Stephens CA. Acute cholecyistitis in children. Surg Gynecol Obstet. 1975;140:16.

[15]. Davidoff AM, Branum GD, Murray EA, Chong WK, Ware RE, Kinney TR, et al. The technique of Laparoscopic cholecystectomy in children. Ann Surg. 1992;215:186-91

[16]. Mattioli G, Pini-Prato A, Castagnetti M, Gandullia P, Toma P, Jasonni V. Is perioperative cholangiography necessary in children undergoing elective lapascopic cholecystectomy? Eur J Pediatr Surg. 2007;17:176-9

[17]. Meshikhes AW. Asymptomatic gallstones in the laparoscopic era. J R Coll Surg Edinb. 2002;47:742-748.

[18]. Vauthey JN, Saldinger PF. The natural history of gallstones and asymptomatic gallstones. In: Blumgart LH, Fong Y, editors. Surgery of the liver and biliary tract. 3rd ed. London: Company LTD, Saunders WB; 2000. pp. 643-649.

[19]. Sakorafas GH, Milingos D, Peros G. Asymptomatic cholelithiasis: is cholecystectomy really needed? A critical reappraisal 15 years after the introduction of laparoscopic cholecystectomy. Dig Dis Sci. 2007;52:1313-1325

[20]. St. Peter SD, Kecklers J, Nari A, Andrews WS, Sharp RJ, Snyder CL, et al. Laproscopic cholecystectomy in the pediatric population. J Laparo Endosc Adv Surg Tech A. 2008;18:127-30

[21]. Peters JH, Ellison EC, Innes JT, Liss JL, Nichols KE, Lomano JM, et al. Safety and efficacy of lapascopic cholecystectomy: A prospective analysis of 100 initial patients. Ann Surg. 1991;213:3-12.

[22]. Graves HA, Ballinger JF, Anderson WJ. Appraisal of lapascopic cholecystectomy. Ann Surg. 1991;213:1073-8.

[23]. Holcomb GW, 3rd, Sharp KW, Neblett WW, 3rd, Morgan WM, 3rd, Pietsch JB. Lapascopic cholecystectomy in infants and children: Modifications and cost analysis. J Pediatr Surg. 1994;29:900-4 